\section{Flow cytometric isolation of a cDNA clone encoding an intracellular protein}

\author{
Manisha Sharma, Kevin D. Barrow, and Glenn M. Smith \\ University of New South Wales, Sydney, NSW, Australia
}

BioTechniques 39:46-50 (July 2005)

\begin{abstract}
Expression cloning is a powerful technique to identify specific genes encoding a protein of interest with unknown sequence. It relies on the biological expression and activity of a cDNA in a host system such as bacteria, yeast, or mammalian cells $(1,2)$. In mammalian cells, a cDNA library can be stably transduced using retroviral expression and screened for the protein of interest. The cDNA is then rescued by PCR (3). Alternately,
\end{abstract} a cDNA library can be transiently transfected into mammalian cells and screened for the protein of interest, followed by isolation of cDNA from clones expressing the protein of interest using Hirt's method, which involves selective precipitation of transiently transfected DNA in mammalian cells (4). The methodology of screening clones expressing a protein of interest was drastically improved with the introduction of an immunological affinity step, where cDNA clones expressing cell surface antigen are physically selected by adhesion over antibody coated dishes (5-8). Although panning protocols have been widely used, irrelevant cells that contaminate the population of true transfectants reduce the cloning efficiency (9-10). Fluorescent-associated cell sorting (FACS) can further improve expression cloning techniques by physically isolating individually labeled cells based on multiparameter selection criterion. High-speed sorting (usually $10^{4}-10^{5}$ cells/min) can greatly increase the number of cells screened and reduce the time involved (11-13). Both panning and FACS protocols have relied on surface expression of the protein, which can be a limiting factor for isolating genes encoding cytoplasmic proteins.

For the first time, we show that FACS can be used to screen a cDNA library to isolate clones expressing intracellular proteins. c-erbB2 protein is overexpressed in cancer cells and has an extracellular transmembrane and intracellular domain. We used a monoclonal antibody (MAb) against the intracellular domain of c-erbB2 protein to screen a cDNA library from HT29 cells (colon carcinoma cell line; from ATCC, Manassas, VA, USA) and enriched the clone of interest using FACS. The complete cDNA library was transfected into Cos 7 cells, which were then fixed, permeabilized, and immunostained with anti-c-erbB2 MAb, followed by fluorescently labeled secondary antibody. Using FACS, the brightest cells were collected, and episomal DNA was extracted, amplified in bacterial cells, transfected into Cos7 cells, and rescreened. The clone of interest showed nearly 10fold enrichment by the second round of sorting. Subsequent screening in the third round resulted in the isolation of a cDNA clone encoding cytoplasmic domain of c-erbB2 protein (adapted from Reference 14).

The exact protocol used in this study was as follows. The messenger RNA (mRNA) from the HT29 cells was isolated using oligo(dT) primers (Invitrogen, Carlsbad, CA, USA). The cDNA was custom synthesized by Stratagene (La Jolla, CA, USA) and cloned into the pBK-CMV ZAP-Express ${ }^{\circledR}$ vector (Stratagene) using EcoRI and XhoI adapters (15). The average size of the insert DNA was $2 \mathrm{~kb}$. The cDNA library was transfected into Cos7 cells (from ATCC), plated on tissue culturetreated Falcon ${ }^{\circledR} 10-\mathrm{cm}$ dishes. Cells were approximately $60 \%$ confluent at the time of transfection. Ten micrograms DNA and $20 \mu \mathrm{L}$ FuGENETM 6 (Roche, Castle Hill, NSW, Australia), prepared according to manufacturer's instruction, were used per dish. Multiple plates were used to transfect a complete representation of the cDNA library $\left(10^{6}\right.$ cDNA clones). FACS was performed $72 \mathrm{~h}$ after transfection, and the cells were harvested, transferred into FACS tubes (BD, Franklin Lakes, NJ, USA), and washed once with phosphatebuffered saline (PBS; calcium- and magnesium-free PBS used throughout; Gibco, Melbourne, VIC, Australia). The cells were passed twice through a 25-G needle (BD), counted, and resuspended at $10^{5}$ cells $/ 100 \mu \mathrm{L}$ in PBS. The cells were fixed and permeabilized with acetone-formaldehyde solution (60\% acetone plus 3\% formaldehyde in $20 \mathrm{mM}$ HEPES; $100 \mu \mathrm{L}$ per $/ 10^{5}$ cells) for $30 \mathrm{~s}$ at room temperature, washed twice with PBS, and finally resuspended in approximately 100 $\mu \mathrm{L} / 10^{5}$ cells in PBS. The cells were next stained with anti-c-erbB2 MAb (clone CB11; Novocastra, Norwell, MA, USA) or isotype-matched antibody (Jackson ImmunoResearch Laboratories, West Grove, PA, USA) (50 ng antibody per $2 \times 10^{5}$ cells) for $30 \mathrm{~min}$ on ice in the dark. The cells were then washed once with $3 \mathrm{~mL} 1 \%$ bovine serum albumin (BSA) in PBS and resuspended in a final volume of $100 \mu \mathrm{L}$. Phycoerythrin (PE)-conjugated anti-mouse antibody (Jackson ImmunoResearch Laboratories) was added according to manufacturer's recommendation and incubated for $30 \mathrm{~min}$ on ice in the dark. Finally, the cells were washed twice with $1 \%$ BSA-PBS and read within $48 \mathrm{~h}$ on the FACS (Laser Scanning Cytometer; CompuCyte, Cambridge, MA, USA) at The University of New South Wales, Sydney. A negative control comprising water-transfected $\operatorname{Cos} 7$ cells treated with antibodies was included. Immunolabeled cells were collected in $1 \%$ BSA-PBS, and episomal DNA was extracted using Puregene ${ }^{\circledR}$ kit (Gentra Systems, Minneapolis, MN, USA). The cells were then pelleted at $10,000 \times g$ for 3 min and resuspended in the residual $30 \mu \mathrm{L}$ solution (from the Puregene kit). Three hundred microliters cell lysis solution (from the Puregene kit) were added to the cell pellet and pipeted up and down to lyse and homogenize the cells. Thirty micrograms proteinase $\mathrm{K}$ were added to the cell lysate, mixed by inversion, and incubated overnight 
at $55^{\circ} \mathrm{C}$. Six micrograms RNase were added to the cell lysate and incubated at $37^{\circ} \mathrm{C}$ for $1 \mathrm{~h}$. The sample was cooled to room temperature, and $100 \mu \mathrm{L}$ protein precipitation solution (from the Puregene kit) were added to the RNAase-treated cell lysate, vortex mixed, incubated on ice for $5 \mathrm{~min}$, and centrifuged at $10,000 \times g$ for $5 \mathrm{~min}$. The supernatant containing the DNA was transferred into a clean microfuge tube, precipitated using $20 \mu \mathrm{g}$ glycogen (Roche) and $300 \mu \mathrm{L}$ 100\% isopropanol. The sample was mixed gently by inverting the tube several times and then incubated on ice for $15 \mathrm{~min}$. The sample was centrifuged at $10,000 \times$ $g$ for $20 \mathrm{~min}$ at $4{ }^{\circ} \mathrm{C}$. The pellet was washed with $70 \%$ ethanol, air-dried, and resuspended in 20-30 $\mu \mathrm{L}$ TrisEDTA (TE) solution. The episomal DNA was electroporated using the Gene Pulser ${ }^{\circledR}$ system (Bio-Rad Laboratories, Hercules, CA, USA) set at 200 ohms, $25 \mu \mathrm{F}$, and $2.2 \mathrm{kV}$, into electrocompetent XLIB cells and plated on kanamycin agar plates.

The histogram in Figure 1 depicts multiparameter detection by FACS. The $x$ - and $y$-axes show the fluorescent intensity of fluorescein 5'-isothiocyanate (FITC) and PE stain (compensated for autofluorescence and endogenous c-erbB2 expression), and gates were set to sort cells (depicted in thick black box). Figure 1A shows $0.13 \%$ of the cells in the gated region for the isotype control. For round 1 of cDNA library screening, $0.24 \%$ of the total cells were collected in the gated region (Figure 1B, total of 6000 cells). To increase the probability of capturing a stained cell, sorting was done in an enrichment mode. This mode enables collection of target cells regardless of the presence of coincident nontarget events (13). Episomal DNA was extracted from these cells, and it was electroporated into electrocompetent XLIB cells. All the bacterial colonies were pooled, and large-scale plasmid DNA was extracted. This DNA was transfected into Cos7 cells and immunolabeled for a second round of sorting on FACS. The sort showed an approximately 10-fold enrichment for the c-erbB2 clones (Figure 1C). Sorting decisions were similar to that in round 1 , except that cells were sorted in a recovery mode. This mode enabled exclusion of target cells coincident with nontarget cells, thus resulting in a higher purity of sorted cells. The gated region contained $1.9 \%$ of the brightest cells, and 12,000 cells were collected. Episomal DNA was extracted, electroporated into XLIB cells, and individual clones were screened. Two out of 25 clones screened showed $2.2 \%$ of immunolabeled cells (Figure 1D). Sequence analysis revealed high homology to the c-erbB2 sequence $\left[\mathrm{P}(\mathrm{N})=5 \times 10^{-20}\right]$. However, the insert encoded a partial c-erbB2 sequence from the $\mathrm{C}$ terminus $(2200 \mathrm{bp})$. The FACS signal from these clones is low, probably due to a low expression level of the gene of interest, or alternately, the transient overexpression of the insert may be toxic to cells. The enrichment of the clone can be improved by using biotinylated probes.

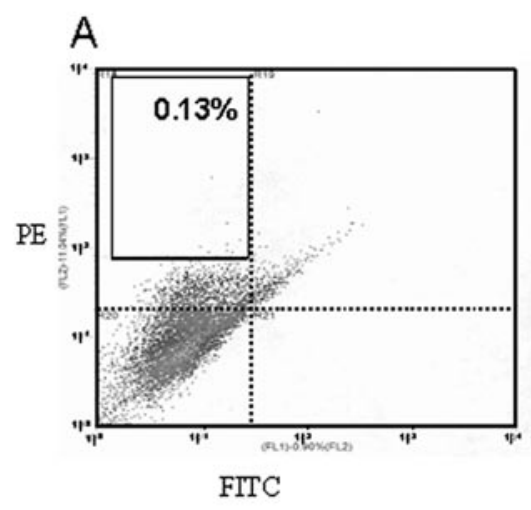

B
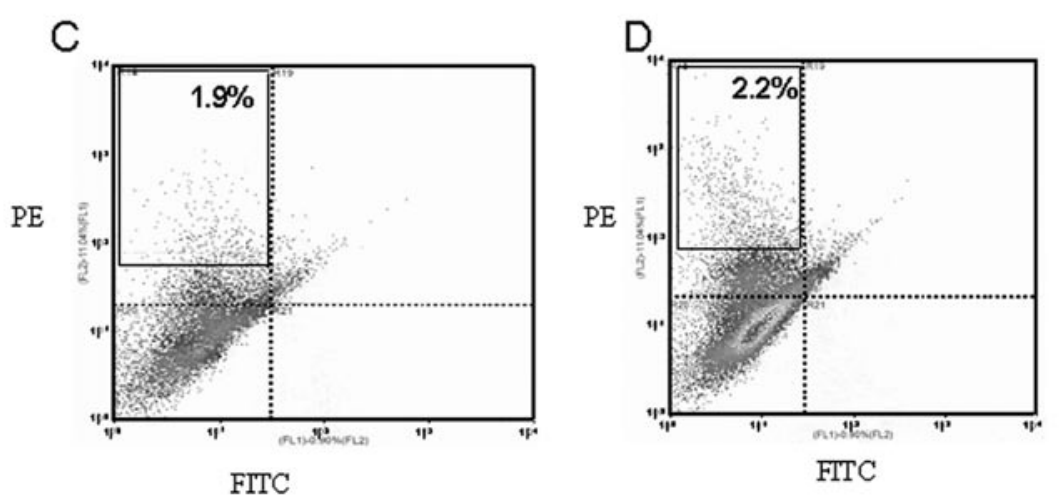

Figure 1. Isolation of c-erbB2 clone from the cDNA library. The HT29 cDNA library was transfected into Cos 7 cells and immunostained with anti-c-erbB2 monoclonal antibody targeted against the intracellular domain of c-erbB2. The $\mathrm{x}$-axis shows fluorescence intensity with fluorescein $5^{\prime}$-isothiocyanate (FITC) stain, and the $y$-axis shows fluorescence intensity with phycoerythrin (PE) stain. (A) Isotype control, used to set gates for sorting. (B) Round 1 sort, $0.24 \%$ of the most fluorescent cells were collected. (C) Round 2 sort, shows an enrichment of the desired clone. (D) Round 3 analysis, individual clone encoding c-erbB2 gene. 


\section{ACKNOWLEDGMENTS}

We would like to thank Rob Wadley for assistance with the flow cytometry and Anne Symthe for valuable discussions. This project was funded by the Cooperative Research Centre (CRC) for Biopharmaceutical Research, and M.S. holds an Australian Postgraduate Award.

\section{COMPETING INTERESTS STATEMENT}

The authors declare no competing interests.

\section{REFERENCES}

1. Lee, F., T. Yokota, T. Otsuka, I. Gemmeli, N. Larson, J. Luh, K.I. Arai, and D. Rennick. 1985. Isolation of cDNA for human granulocyte-macrophage colony-stimulating factor by functional expression in mammalian cells. Proc. Natl. Acad. Sci. USA 82:4360-4364.

2. Wong, G.G., J.A. Witek, P.A. Temple, K.M. Wilkens, A.C. Leary, D.P. Lexenberg, S.S. Jones, E.I. Brown, et al. 1985. Molecular cloning of the complementary DNA and purification of the natural and recombinant proteins. Science 228:810-815.

3. Kitamura, T., M. Onishi, S. Kinoshita, A. Shibuya, A. Miyajima, and G.P. Nolan. 1995. Efficient screening of reteroviral cDNA expression libraries. Proc. Natl. Acad. Sci. USA 92:9146-9150.

4.Hirt, B. 1967. Selective extraction of polyoma DNA from infected mouse cell cultures. J. Mol. Biol. 26:365-369.

5. Aruffo, A. and B. Seed. 1987. Molecular cloning of a CD28 cDNA by a high efficiency COS cell expression system. Proc. Natl. Acad. Sci. USA 84:8573-8577.

6. Schaffer, J.E. and H.F. Lodish. 1994. Expression cloning and characterisation of a novel adipocyte long chain fatty acid transport protein. Cell 79:427-436.

7.Seed, B. and A. Aruffo. 1987. Molecular cloning of the CD2 antigen, T-cell erythrocyte receptor, by a rapid immunoselection procedure. Proc. Natl. Acad. Sci. USA 84:33653369.

8. Simmons, D.L., A.B. Satterthwaite, D.G. Tenen, and B. Seed. 1992. Molecular cloning of a cDNA encoding CD34, a sialomucin of human hematopoietic stem cells. J. Immunol. 148:267-271.

9. Gearing, D.P, J.A. King, N.M. Gough, and N.A. Nicola. 1989. Expression cloning of a receptor for human granulocyte-macrophage colony-stimulating factor. EMBO J. 8:36673676.

10.Pholenz, J., L. Duprez, R.E. Weiss, G. Vassart, S. Refetoff, and S. Costagliola. 2000. Failure of membrane targeting causes the functional defect of two mutant sodium io- dide symporters. J. Clin. Endocrinol. Metab. 85:2366-2369.

11.Puchalski, R.B. and W.E. Fahl. 1992. Gene transfer by electroporation, lipofectamine, and DEAE dextran transfection: compatibility with cell-sorting by flow cytometry. Cytometry 12:23-30.

12.Rice, G.C., D. Pennica, J.A. Borree, and S.R. Williams. 1991. Measurement of transient cDNA expression in mammalian cells usig flow cytometric cell analysis and sorting. Cytometry 12:221-233.

13.Daugherty, P., B.L. Iverson, and G. Georgiou. 2000. Flow cytometric screening of cell based libraries. J. Immunol. Methods 243:211-227.

14.Hollenbaugh, D., A. Aruffo, B. Jones, and P. Linsley. 2004. Use of monoclonal antibodies for expression cloning, p. 6.11.11-16.11.16. In F.M. Ausubel, R. Brent, R.E. Kingston, D.D. Moore, J.G. Seidman, J.A. Smith, and K. Struhl (Eds.), Current Protocols in Molecular Biology. John Wiley \& Sons, New York.

15.Stratagene and Z.-E.E.X.L.C.a.P. libraries. 1996. ZAP-Express EcoRI/XhoI Library (Custom and Premade Libraries). Stratagene, La Jolla, CA.

Received 21 October 2004; accepted 19 April 2005.

Address correspondence to Manisha Sharma and Kevin Barrow, School of Biotechnology and Biomolecular Sciences, University of New South Wales, Sydney 2052, NSW, Australia.e-mail:manisha1575@yahoo.com.au
To purchase reprints
of this article, contact apfeffer@BioTechniques.com 